\title{
Frontal and sagittal imbalance in patients with adolescent idiopathic deformity
}

\author{
Ozren Kubat ${ }^{1}$, Dror Ovadia ${ }^{2}$ \\ ${ }^{1}$ Department of Orthopaedic Surgery, Clinical Hospital Centre Zagreb, Zagreb, Croatia; ${ }^{2}$ Dana Dwek Children's Hospital, Tel Aviv Medical Center, \\ Tel Aviv, Israel \\ Contributions: (I) Conception and design: All authors; (II) Administrative support: D Ovadia; (III) Provision of study materials or patients: O Kubat; \\ (IV) Collection and assembly of data: O Kubat; (V) Data analysis and interpretation: All authors; (VI) Manuscript writing: All authors; (VII) Final \\ approval of manuscript: All authors. \\ Correspondence to: Ozren Kubat, MD. Department of Orthopaedic Surgery, Clinical Hospital Centre Zagreb, Salata 6-7, 10000 Zagreb, Croatia. \\ Email: ozren.kubat@gmail.com.
}

\begin{abstract}
The human spinal column underwent many significant changes over the 4.5 million years of our ancestral bipedalism. The main change, however, came with acquiring multiple curvatures in the sagittal plane. This alteration seems to have exposed a weakness in our body's keystone and made us susceptible to thus far unbeknown problems of the spine because it has been noted that idiopathic scoliosis has not been observed in other primates. Adolescent idiopathic scoliosis (AIS) is a three-dimensional deformity of the spine causing an imbalance of the trunk as it increases in magnitude. A scoliotic curve comprises three components, the coronal, sagittal, and axial so that each curve can affect the global balance of the body differently. Patients with significant scoliotic deformities often find themselves at a biomechanical disadvantage when it comes to energy expenditure and keeping an upright stance. The pioneers of scoliosis research recognized the need for describing and quantifying deformity to better understand it, so they first translated clinical measurements to radiographs and built from there. The development of concepts like defining a curve by its end vertebrae and measuring its magnitude, assessing global spinal balance, describing the stable zone, and pinpointing the stable vertebra all followed suit. The importance of sagittal balance and restoring sagittal parameters during treatment was emphasized. In a quest to bring order to chaos, some tried to classify various scoliotic curve types. These classifications helped steer treatment decisions but were found lacking in many aspects. So far, a widely accepted three-dimensional classification of scoliosis still does not exist. This review aims to provide the reader with an overview of the development of balance and imbalance concepts in scoliosis.
\end{abstract}

Keywords: Adolescent; kyphosis; lordosis; scoliosis; spine

Submitted Sep 02, 2019. Accepted for publication Oct 08, 2019.

doi: 10.21037/atm.2019.10.49

View this article at: http://dx.doi.org/10.21037/atm.2019.10.49

\section{Introduction}

The term scoliosis, derived from the Greek word meaning "crooked", was first used as regarding spinal deformities by Hippocrates (460-370 BC) $(1,2)$. However, in his works, this term is given a generic meaning, referring to almost any type of spinal curvature. One of his successors, Galen of Pergamon (129-210 AD) commented on Hippocrates' flawed use of the term, and described four types of spinal deformities-kyphosis when the spine moves backward, lordosis when propelled forward, scoliosis as it shifts to the side and succussion, a situation without any deformity but with movement of the intervertebral articulations (3). So, it is Galen who is credited for the first use of this term as it is used today.

Modern orthopedic surgery defines scoliosis as a lateral 
curvature of the spine greater than $10^{\circ}$ measured on a posteroanterior (PA) radiograph, a method introduced by Cobb in 1948 (4). This is a complex deformity, comprising changes in all three anatomical planes: a lateral shift in the coronal, straightening or bowing in the sagittal, and rotation around the vertebral axis in the axial plane (5). The most significant changes are in the apex of the curve, and as the deformity progresses, it brings upon structural changes of the vertebrae and the rib cage. This three-dimensional (3D) spinal deformity also invariably influences the spinopelvic alignment.

Adolescent idiopathic scoliosis (AIS) is by far the most common type of scoliosis, with a prevalence of $2-3 \%$ in children aged 10 to 16 years, with girls bearing a larger risk for progression, by a ratio of 3.6:1 (6). Various etiologies for AIS have been proposed in the literature, with one of the theories focusing on a deficit in postural balance which could result in scoliosis (7-11). Herman et al. found a cause of AIS in a sensory rearrangement of the motor system on the representation of the body in space (12). Failure of determining the center of pressure $(\mathrm{CoP})$ position concerning the body's center of mass (CoM) due to a sensory integration disorder could cause balance maladjustment in AIS (13). Beaulieu et al. confirmed this sensory integration disorder in the basis of scoliosis, and assumed a two-staged process of spinal deformity development: in the initial stage, a small curve is caused by a defect of the neuromuscular and sensorimotor system, while in the second stage the increase of the curve and neurological dysfunction disturb the ability to recalibrate the $\mathrm{CoP}$ position in relation to $\mathrm{CoM}$, namely postural balance (14).

Problems of global balance affect patients with every type of scoliosis, from the mildest to the most difficult cases, untreated ones, the ones undergoing brace treatment, as well as those who have had surgery for their deformity. The purpose of this article is to summarize and reevaluate today's knowledge of the issues of spinal balance in AIS.

\section{Frontal (IM) balance in AIS}

The spinal column is the keystone of the body, and deformations that cause it to fall out of balancedecompensate, do so to the entire trunk. Clinically, the examiner can assess spinal balance by dropping a plumb line from the midpoint of the occiput and measure its distance from the gluteal crease. Rudicel and Renshaw used this method on a standing radiograph by measuring the horizontal distance between a vertical line from the midpoint of the occiput or the highest depicted vertebra, and the other from the midline of the sacrum (15). Floman et al. observed that many patients exhibit satisfactory alignment of the head over the pelvis yet show a significant shift of the trunk away from the midline (16). Harrington devised the premise of the stable zone which is supposed to contain the lower instrumented vertebra, defined by two vertical lines drawn through the lumbosacral facets (17). King et al. worked to improve pinpointing the accuracy of the stable zone's location and instituted a reference line called the central sacral line (CSL), a single vertical line from the midline of the sacrum perpendicular to the iliac crests (18). The vertebra most closely bisected by this line is considered the stable vertebra. The authors emphasized the importance of basing this line on a horizontal pelvis, so any leg length discrepancy always needs to be addressed before taking the radiograph (18).

There is no uniformity in reporting spinal compensation/ decompensation in the literature (19). Some authors use the position of the head, while others rely on the position of the thorax over the pelvis $(16,18,20-27)$. According to the Scoliosis Research Society (SRS), "compensation" is the vertical alignment of the center of $\mathrm{C} 7$ vertebra over the midpoint of the sacral plateau in the coronal plane. This alignment is designated as coronal (frontal) balance (CB), and it refers to the position of the head with the pelvis (Figure 1) (29). Consequently, decompensation in AIS is a deviation of the $\mathrm{CB}$ axis from normal, usually for more than 2.0 centimeters. Measuring the position of the thorax with the pelvis, on the other hand, can be done in two ways. One, invented by Floman et al. using the lateral trunk shift (LTS), measured as the horizontal distance from the center of the pelvis to a point bisecting the line between the edges of the most peripherally displaced ribs (Figure 2) $(16,25)$. The other method, thoracic apical vertebral translation (tAVT), is performed by measuring the distance from the center of the apical vertebra in the thoracic spine to a vertical dropped from the $\mathrm{C} 7$ vertebra $(21,22,30)$. The lumbar spine can also be the cause of a loss of balance, so lumbar apical vertebral translation (l AVT) is measured as the distance from the center of the lumbar apical vertebra to the center sacral line (30). Richards found that the trunk shift was more accurate in anticipating spinal balance than the C7 alignment with the sacrum (25).

Matters of the frontal balance (FB) of the spine came into the spotlight with the advent of surgical treatment for scoliosis, as surgeons tried to decide on which areas to include in the fusion, a matter still heavily debated 


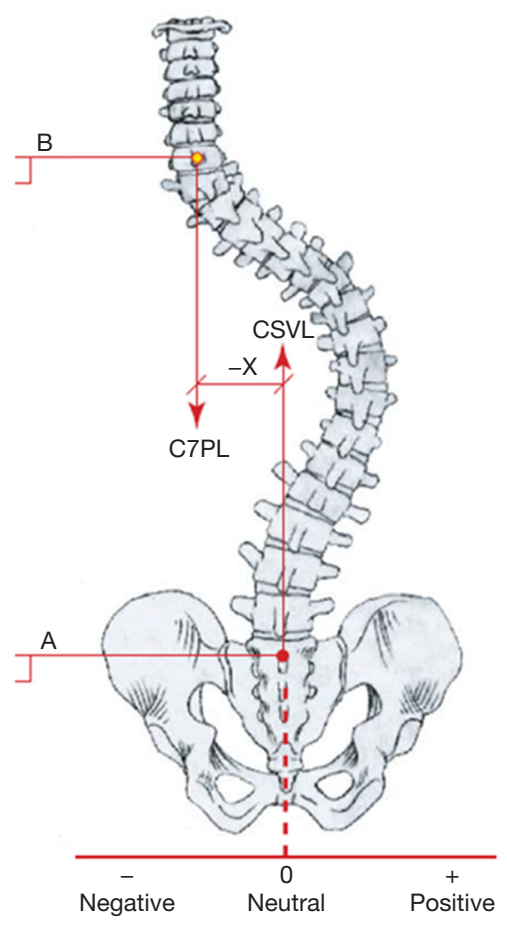

Figure 1 Coronal balance. The C7PL is dropped from the center of the $\mathrm{C} 7$ vertebra in the same way it is done clinically and drawn parallel to the vertical edge of the image. The CSVL is drawn upward from the middle of S1, parallel to the vertical edge of the radiograph. In a healthy and balanced spine, these lines coincide. Offset between the C7PL and CSVL marks an imbalance in the coronal plane, easily quantified in millimeters by the formula B $\mathrm{A}= \pm \mathrm{X}$. Image courtesy of Scoliosis Research Society, from (28). C7PL, plumb line dropped from C7 vertebra; CSVL, center sacral vertical line.

today. Surgical treatment of AIS strives to achieve fusion in the desired vertebral segments, provide optimal balance in coronal and sagittal planes by correcting the curve(s) through fusing the least motion segments of the spine as possible. The first fusion of a scoliotic spine was performed by Hibbs in year 1914, who presented the idea of fusing the spine to vertebrae that end up parallel to each other after application of the turnbuckle cast (31). For a thoracic pattern curve, the pioneering authors agreed on the need to fuse all levels that make up the curve (32-34). Harrington, who introduced an instrumented fusion with his rod in 1953, suggested being on the safe side by fusing above and up to two vertebrae below the curve itself (35). Moe and Goldstein stressed the importance of vertebral rotation

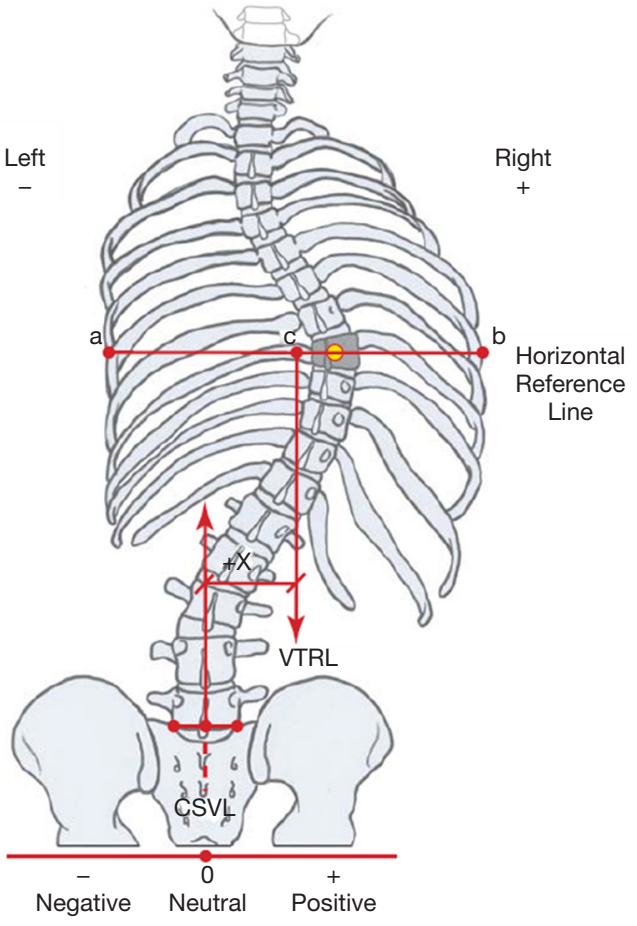

Figure 2 Coronal trunk shift. Thoracic trunk shift is measured on upright PA (or AP) radiographs. First, the thoracic apical vertebra needs to be identified, and its center marked. A horizontal line is drawn through the center, and the edges of the apical ribs are marked. The midpoint between the two edge points is marked, and a perpendicular line is dropped as reference. This line is referred to as the vertical trunk reference line, and the trunk shift is measured as the linear distance in millimeters between this line and the CSVL. Shift to the right is marked as a positive and to the left of the CSVL a negative value. Image courtesy of Scoliosis Research Society, from (28). PA, posteroanterior; CSVL, center sacral vertical line.

and advocated fusion from the superior to inferior neutrally rotated vertebrae, introducing the selective thoracic fusion concept (36-39). Some 30 years after the Harrington rod, King et al. characterized five thoracic curve types and guided on determining fusion levels for each type, but advocated carrying the fusion down to the stable vertebra (18). They also introduced a term called the "flexibility index", used to compare the flexibility of the thoracic and lumbar curves by calculating the difference in percent of correction between the thoracic and lumbar curve on supine bending radiographs. This helped differentiate between certain curve types (18). According to Moe and King, selective thoracic fusion could achieve and keep a good balance of the spine if a proper lower instrumented vertebra was chosen. 
Spontaneous correction of the unfused lumbar curve was noted that helped balance out the newly-corrected thoracic curve (40). This correction was often found to be smaller than the one seen on preoperative bending images (22,41-43). Winter et al. posit that correcting a curve beyond its flexibility is an overcorrection, which causes problems in the balance of the compensatory curves (44). The balance of the fusion mass is important for adjacent segment disease occurring over time. An additional parameter was created by Frez et al. called the rod to center sacral line distance (RCSLD), rating how centered and balanced the fusion mass is to help quantify this. It consists of measuring the distance of the Harrington rod to the CSL at the cephalad and caudal ends of the instrumentation. The authors noted a gradual correction of the RCSLD (and with it, the fusion mass) happening over time, rather than a direct instant improvement (22).

As said before, coronal spinal balance showed improvement over time after Harrington instrumentation (23). A significant change in achieving correction and balancing out scoliosis came with the ascent of the Cotrel-Dubousset instrumentation in 1983. Different kind of correction was made possible by derotating or, rather, translating a scoliotic curve for (ideally) $90^{\circ}$ about the longitudinal spinal axis (45). This maneuver showed great strength of correction, but as the experience with this new instrumentation grew, so did the frequency of reports on postoperative trunk balance issues $(20,46,47)$. The derotation (translational) maneuver produced torsion changes in the non-fused areas of the spine, resulting in the imbalance. It was also recognized that levels chosen for correcting and balancing out scoliosis (King 2 curve) using the Harrington rod were not suitable for the CD instrumentation (20). Arlet et al. challenged the premise of the rod de-rotation maneuver being the main culprit for balance issues after CD instrumentation and surmised that the decompensation in question is a result of a lack of symmetry between the different curves, instrumentation notwithstanding (48).

Eighteen years after King, a new system of characterizing scoliotic curves emerged, as Lenke et al. published their classification, with significantly better inter- and intrarater reliability (49). They described six types of scoliosis and introduced a "lumbar spine modifier" stemming from the relation of the center sacral vertical line (CSVL) to the lumbar apical vertebra. This is different from King's CSL, the CSVL of Lenke ignores pelvic obliquity $<2 \mathrm{~cm}$ (49). This classification gave almost equal value to the coronal and sagittal plane and emphasized the importance of sagittal balance by accounting for kyphosis and lordosis as key factors in determining fusion levels.

Cobb was the first to describe major and minor, as well as structural and non-structural curves and Lenke et al. built upon that by creating a reproducible way of determining curve type (4). According to Lenke et al., the major curve is one of the greatest magnitudes, and it is inherently structural, while the minor curve can be either structural or nonstructural. A curve which corrects to less than $25^{\circ}$ on maximum effort side-bending radiographs is considered nonstructural (49). The nonstructural curves balance out the structural deformity on the scale of the entire spine; however, over time, it too can increase and become structural. Lenke classification undoubtedly came as a major improvement; however, its downside is failing to address the axial plane and rotation of the spine to provide the ultimate 3D surgical decision guide.

\section{Sagittal (IM) balance in AIS}

The acquisition of erect posture and consequent bipedalism represent the most important evolutionary adjustment for our species. The earliest hominid with a bipedal specialization is the Ardipithecus ramidus, dating back to 4.4 million years ago (50). However, it was not until the emergence of Homo erectus some 1.9 million years ago that hominids grew long legs and became exclusively terrestrial (51). This change not only broadened the scope of our gaze and freed our hands for greater endeavors, but also caused significant changes in our spinal column. Being upright forced our spine to assume an S-shape when viewed from the side (Figures 3,4). It is this shape that allows for even weight distribution and movement flexibility, through subsequent opposing curves. Hominids became the only species in existence with a lordosis of the lumbar spine (52). The newborn infant of the Homo sapiens has a straight spine. Cervical lordosis (CL), thoracic kyphosis (TK) and lumbar lordosis (LL) develop through upright stance and progressive ambulation. The LL, dependent on the shape of the pelvis, influences the TK and gives it its size and shape, which again drives the shape of the CL. The incident, or a combination thereof, that spark scoliosis in some children remain unknown, but the upright sagittal spinal biomechanics undoubtedly play a paramount role $(53,54)$.

Assessing global sagittal balance in patients with scoliosis is extremely important, especially before surgery, because it can help avoid complications of imbalance, the progression of deformity, adjacent segment disease, and pseudarthrosis. 


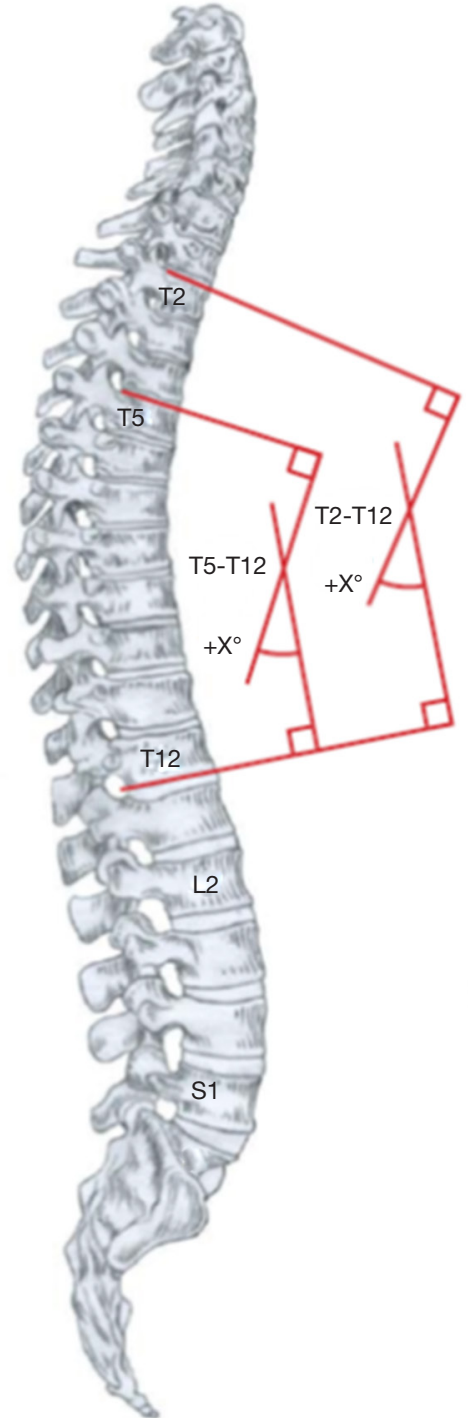

Figure 3 Thoracic sagittal alignment. Thoracic kyphosis is measured from the upper-endplate of $\mathrm{T} 2$ to the lower endplate of T12 using the Cobb method. The upper thoracic spine is the most difficult to image, and it is a common occurrence not to have a clear shot of T2 on a radiograph, due to superposition of overlapping structures. Proximal thoracic kyphosis is measured from the upper-endplate of T2 to the lower endplate of T5. Mid/ lower thoracic kyphosis is measured from the upper-endplate of T5 to the lower endplate of T12. Image courtesy of Scoliosis Research Society, from (28).

A balanced posture is achieved when the spine and pelvis are aligned in a way that provides horizontal gaze with minimal energy output. Although a whole battery of parameters exists, evaluation of global spinal balance (both sagittal and

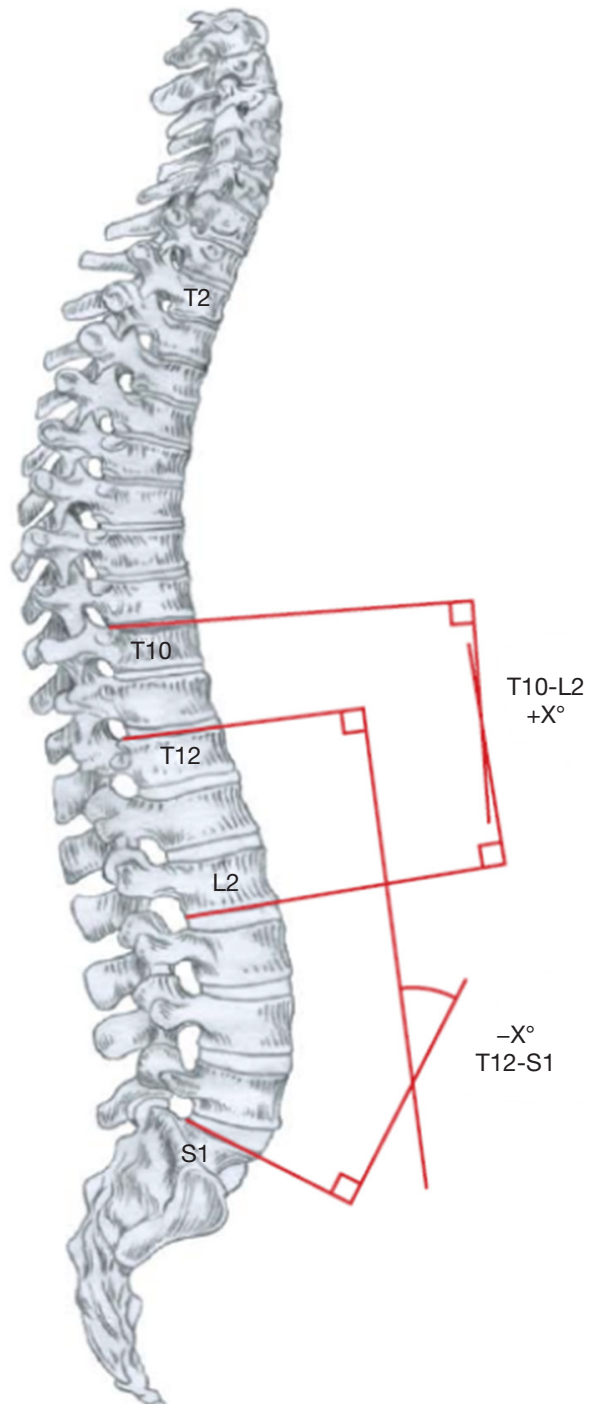

Figure 4 Thoracolumbar/lumbar sagittal alignment. Thoracolumbar sagittal alignment is measured from the upper-end plate of T10 to the lower endplate of L2 using the Cobb method. Lumbar sagittal alignment is measured from the upper-end plate of T12 to the S1 endplate. The S1 endplate can sometimes be difficult to identify by a straight line, so an alternative is to draw a line perpendicular to the posterior sacral cortex and draw a perpendicular to it at the level of S1. Image courtesy of Scoliosis Research Society, from (28).

frontal) is usually done by measuring the sagittal vertical axis (SVA) and FB on plain radiographs $(55,56)$. In the sagittal plane, the position of the center of $\mathrm{C} 7$ vertebra is assessed with the femoral head axis and the posterior edge 


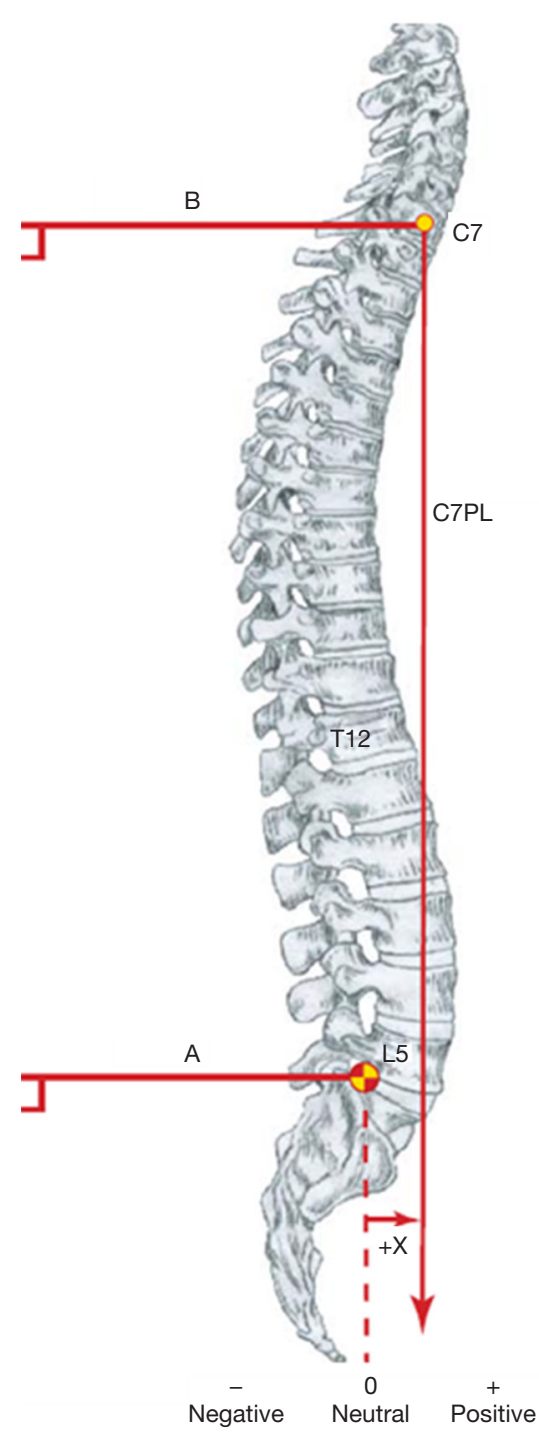

Figure 5 Sagittal balance. The center of C7 vertebra is marked, and a plumb line has dropped perpendicular to the vertical edge of the radiograph. The posterosuperior corner of S1 is also marked, and a line perpendicular to the vertical edge of the radiograph is constructed. The horizontal difference measured in millimeters between these two lines gives the sagittal balance. No difference between the lines equals sagittal balance. Migration of the line to the front is marked as a positive value, while the movement to the back is negative. Image courtesy of Scoliosis Research Society, from (28).

of the sacral plate. The $\mathrm{C} 7$ was chosen as a reference point over $\mathrm{T} 1$ because of the visibility on lateral radiographs. The plumb line dropped from C7 vertebra (C7PL) is ideally located at the posterior edge of the sacral plateau, and this position is deemed very stable, while displacement in front or behind this point shows an unstable situation (Figure 5). Measurement of C7PL excursion should be done on calibrated radiographs. The observed migration of C7PL backward from childhood to adulthood is normal, however, in scoliosis and degenerative spinal changes, it is often placed anterior to the femoral heads $(57,58)$. Pasha et al. reported that SVA, sagittal pelvic parameters, T4-T12 kyphosis, and frontal Cobbs all exert a relevant influence on postural balance in AIS (59). Mac-Thiong et al. consider measuring global balance using linear parameters to be error-prone and suggest including the spinal-sacral angle, spinal tilt angle, and spinal-pelvic tilt angle to the evaluation to improve on the accuracy (58).

Dickson $e t$ al. reported that asymmetry in the median (mid-sagittal) plane is the essential lesion in the advent and progression of idiopathic scoliosis, using flattening or even reversing normal TK to a lordosis at the apex of deformity $(60,61)$. The authors further claim that the increase in anterior apical vertebral height combined with distortion of the posterior end-plate suggest that AIS has a similar, only reversed pathological process to that of Scheuermann's disease $(60,62)$. Reduction of TK, seen mostly in thoracic scoliotic curves, has been well reported in the literature (56,60,63-67). Small TK in patients with thoracic AIS curves is related to a disturbance of vertebral body growth, which shows the greatest influence on TK comes from the shape of the vertebrae and intervertebral discs $(65,68)$. This reduction cannot remain isolated in a closed, interdependent system such as the human spine. An interesting finding of a CL volte-face to a kyphosis with an average value of $10 \pm 18^{\circ}$ was reported by Roussouly et al. in their series of 132 AIS patients before surgery (56). Hilibrand $e t a l$. were the first to note a significant inverse relationship between thoracic and cervical kyphosis and hypothesized the changes to be compensation to permit a horizontal line of vision (69).

The lumbar spine acts as a link between the pelvis and upper segments of the spine and is a failsafe with the ability to compensate for changes in the thoracic levels to give an overall balanced result, especially after surgical treatment for the selective fusion of isolated thoracic curves (70). The observation that the young population tolerates imbalance better than the adults stems from a LL of greater magnitude and higher mobility that they exhibit. Determining the LL limits is not always straightforward, and the method that produces most accurate measurements is by using the inflection point of Berthonnaud for the proximal limit, where TK transitions into LL (71). The LL is not strongly 


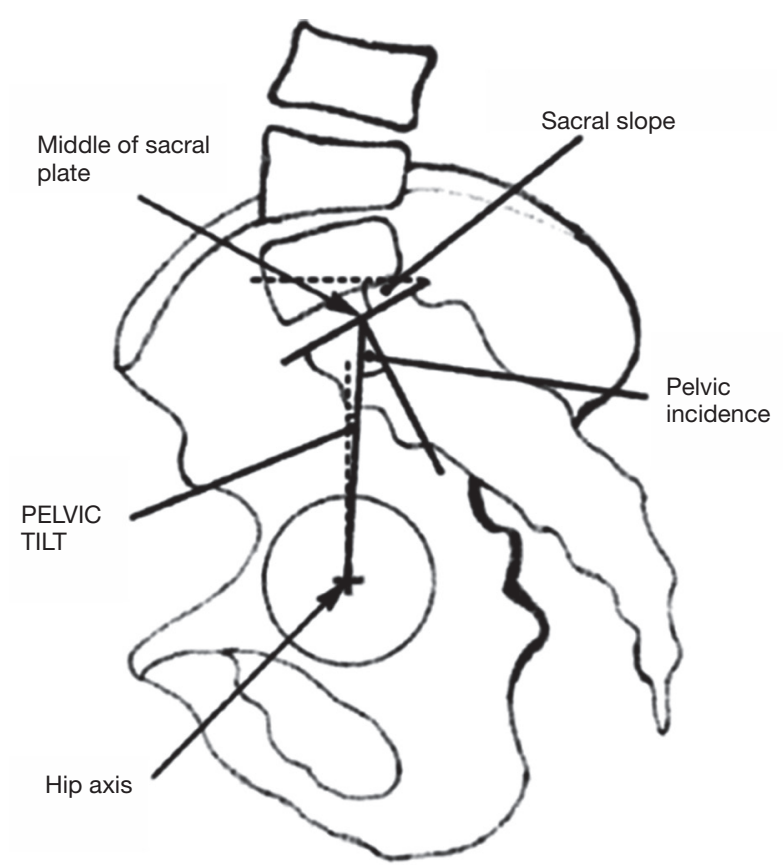

Figure 6 Spinopelvic parameters. Sagittal pelvic parameters assessed from the standing lateral radiograph (in AIS, while in non-ambulating children with EOS the spinopelvic parameters can also be measured on sitting radiographs). Landmarks needed for measurement are the hip axis (located in the middle of the line connecting the centers of the femoral heads) and the middle of the sacral plate. Pelvic incidence is always equal to the sum of pelvic tilt and sacral slope. Image provided courtesy of Spine LWW, from (65). AIS, adolescent idiopathic scoliosis.

influenced by spinal morphology, as opposed to TK, its' main driver is the pelvic geometry, especially the sacral slope (SS) which is robustly affected by the value of pelvic incidence (PI) (72-77). Legaye et al. reported a value of LL equal the sum of PI plus $10^{\circ}$, while TK resembles PI (73). Literature shows that values for sagittal alignment of the spine are aberrant in AIS across the board, but the pelvic alignment remains ever so slightly disrupted $(56,65,78,79)$. All the measurements stated above may be of little practical meaning, as many would argue that measuring kyphosis and lordosis on a lateral radiograph is inconsequential because it does not depict the true sagittal shape of the spine and distorts the understanding of sagittal biomechanical loading $(61,67,80)$. However, going into too much detail using a $3 \mathrm{D}$ classification system based on an assessment of geometric torsion and vertebral morphometry is too complex to be used in a busy clinical setting (81).

Spinopelvic balance assessment, conceived by Duval-
Beaupére, is based on the formula stating that PI equals the sum of pelvic tilt $(\mathrm{PT})$ and $\mathrm{SS}(\mathrm{PI}=\mathrm{PT}+\mathrm{SS})$ (Figure 6) $(73,82)$. PI is an intrinsic, anatomical parameter, constant during childhood and slowly growing until adulthood, while PT and SS are positional parameters able to change through rotation of the pelvis around the femoral heads $(52,79,83)$. The value of PI is significantly increased in AIS patients at $57.3 \pm 13.8^{\circ}$ when compared to values of $51 \pm 9.7^{\circ}, 46.8 \pm 11.2^{\circ}$, and $47.4 \pm 7.5^{\circ}$, respectively, seen in normal adolescents $(65,73,75,84)$. Sagittal position of the pelvis, as determined by the PI value, shows the ability of the pelvis to compensate for any imbalance. A low PI value does not allow for much retroversion of the pelvis, while the situation in a high PI setting means that a bigger PT angle is possible. The PT can be further limited by a hip extension (52). The minimal value of SS is $0^{\circ}$, equating to a horizontal sacral plate. A negative value of SS is not possible in upright subjects (52). As noted, before, PI determines the size of the LL-low PI values (vertical pelvis) equal a tendency for a flatter lordosis, while high PI (horizontal pelvis) is associated with marked lordosis (73).

\section{Conclusions}

As our understanding of scoliosis biomechanics progressed, and our instrumentations gave us more power and precision, a strategic shift occurred in spinal surgery. Instead of aiming for maximal correction of the scoliotic curve, we now understand attaining the best possible coronal and sagittal balance in conjunction with curve correction is paramount in AIS treatment. This review attempts to provide the reader with an overview of the landmark discussions on spinal balance in AIS. When treading through the vast literature on this topic, one can easily be overwhelmed by the inconsistencies from how a radiograph is taken to the way parameters are measured. As Bernhardt and Bridwell, who gave us the norm ranges of TK $\left(20-50^{\circ}\right)$ and LL $\left(20-60^{\circ}\right)$ in the 1980 s emphasized, "for valid comparison of measurements, the levels and methods of measurement should be well defined" (85). We believe it would be beneficial for the worldwide spinal community to make a broad-reaching organized effort in promoting uniformity across the board.

Knowing and understanding the different spinal and pelvic parameters and landmarks which provide us the information on the anatomical position of the spine and pelvis is mandatory for today's spinal surgeons. Over the years, the sagittal balance has taken the spotlight away 
from the balance in the coronal plane, so it is now widely appreciated how much fine-tuning the sagittal spinal profile benefits the patients. However, in the end, the main goal of surgery when treating any spine deformity remains to be a spine that is well balanced in all 3 anatomical planes.

Many tried to help by providing cookbooks of a sort so that everyone could choose the correct fusion levels and achieve the ultimate balanced spine in AIS patients to last them a lifetime. However, so far, every system of classifying scoliotic curve fell short of the holy grail. Modern technologies in diagnostics, such as the EOS system, together with work in the field of 3D spinal morphology may provide us with the ultimate classification to improve our results in taking care of AIS patients (86-91). Valuable input is also coming from authors studying early-onset scoliosis, as Spurway et al. presented their new method of measuring the true length of a spine affected by scoliosis, so we can better rate the all-important spinal growth during treatment and follow-up (92).

\section{Acknowledgments}

None.

\section{Footnote}

Conflicts of Interest: The authors have no conflicts of interest to declare.

Ethical Statement: The authors are accountable for all aspects of the work in ensuring that questions related to the accuracy or integrity of any part of the work are appropriately investigated and resolved.

\section{References}

1. Marketos SG, Skiadas PK. Hippocrates: The Father of Spine Surgery. Historical Perspective. Spine 1999,24:1381-7.

2. Moe JH. Historical aspects of scoliosis. In: Moe JH. editor: Moe's textbook of scoliosis and other spinal deformities. Philadelphia: Saunders, 1987:1.

3. Marketos SG, Skiadas PK. Galen: A pioneer of spine research. Spine 1999;24:2358-62.

4. Cobb JR. Outline for the Study of Scoliosis. The American Academy of Orthopaedic Surgeons Instructional Course Lectures 1948;5:261-75.

5. Magny A. editor. Mémoire sur le Rakitis ou Maladie de la
Colonne vertebrale. Paris: Chez Méquignon l'aîné, 1780.

6. Weinstein SL. Adolescent idiopathic scoliosis: prevalence and nature history. In: Weinstein SL. Editor. The paediatric spine: principle and practice. New York: LWW, 1994:463-78.

7. Ford DM, Bagnall KM, Mc Fadden KD, et al. Paraspinal muscle imbalance in adolescent idiopathic scoliosis. Spine 1984;9:373-6.

8. Ford DM, Bagnall KM, Clements CA, et al. Muscle spindles in the paraspinal musculature of patients with adolescent idiopathic scoliosis. Spine 1988;13:461-5.

9. Veldhuizen AG, Weber D, Webb P. The aetiology of idiopathic scoliosis: biomechanical and neuromuscular factors. Eur Spine J 2000;9:178-84.

10. Lowe TG, Chir M, Margulies J, et al. Etiology of idiopathic scoliosis: current trends in research. J Bone Joint Surg 2000;82:1157-68.

11. Yamada K, Yamamoto H, Nakagawa Y, et al. Etiology of idiopathic scoliosis. Clin Orthop Relat Res 1984;184:50-7.

12. Herman R, Mixon J, Fisher A, et al. Idiopathic scoliosis and the central nervous system: a motor control problem. Spine 1985;10:1-14.

13. Lidström J, Friberg S, Lindstrom L, et al. Postural control in siblings to scoliosis patients and scoliosis patients. Spine 1988;13:1070-4.

14. Beaulieu M, Toulotte C, Gatto L, et al. Postural imbalance in non-treated adolescent idiopathic scoliosis at different periods of progression. Eur Spine J 2009;18:38-44.

15. Rudicel S, Renshaw TS. The effect of the Milwaukee brace on spinal decompensation in idiopathic scoliosis. Spine 1983;8:385-7.

16. Floman Y, Penny JN, Micheli LJ, et al. Osteotomy of the fusion mass in scoliosis. J Bone Joint Surg 1982;64:1307-16.

17. Harrington PR. Technical details in relation to the successful use of instrumentation in scoliosis. Orthop Clin North Am 1972;3:49-67.

18. King HA, Moe JH, Bradford DS, et al. The selection of fusion levels in thoracic idiopathic scoliosis. J Bone Joint Surg 1983;65:1302-13.

19. Richards BS, Scaduto A, Vanderhave K, et al. Assessment of trunk balance in thoracic scoliosis. Spine 2005;30:1621-6.

20. Moore MR, Baynham GC, Brown CW, et al. Analysis of factors related to truncal decompensation following Cotrel-Dubousset instrumentation. J Spinal Disord 1991;4:188-92.

21. Edwards CC, Lenke LG, Peelle M, et al. Selective thoracic 
fusion for adolescent idiopathic scoliosis with $\mathrm{C}$ modifier lumbar curves: 2- to 16-year radiographic and clinical results. Spine 2004;29:536-46.

22. Frez R, Cheng JC, Wong EM. Longitudinal changes in trunkal balance after selective fusion of King II curves in adolescent idiopathic scoliosis. Spine 2000;25:1352-9.

23. Bassett GS, Hensinger MC, Keiper MD. Effect of posterior spinal fusion on spinal balance in idiopathic scoliosis. J Pediatr Orthop 1989;9:672-4.

24. McCance SE, Denis F, Lonstein JE, et al. Coronal and sagittal balance in surgically treated adolescent idiopathic scoliosis with the King II curve pattern. A review of 67 consecutive cases having selective thoracic arthrodesis. Spine 1998;23:2063-73.

25. Richards BS. Lumbar curve response in type II idiopathic scoliosis after posterior instrumentation of the thoracic curve. Spine 1992;17:S282-6.

26. Bassett GS, Bunnell WP. Effect of a thoracolumbosacral orthosis on lateral trunk shift in idiopathic scoliosis. J Pediatr Orthop 1986;6:182-5.

27. Ouellet JA, Johnston CE 2nd. Effect of grafting technique on the maintenance of coronal and sagittal correction in anterior treatment of scoliosis. Spine 2002;27:2129-35.

28. O'Brien MF, Kuklo TR, Blanke KM, et al. editors. Spinal Deformity Study Group Radiographic Measurement Manual. Memphis, TN: Medtronic Sofamor Danek, 2004.

29. Scoliosis Research Society. Medical Professionals: Glossaries [Internet]. 2019 [cited 2 August 2019]. Available online: https://www.srs.org/professionals/ online-education-and-resources/glossary/threedimensional-terminology-of-spinal-deformity

30. Lenke LG, Bridwell KH, Baldus C, et al. Preventing decompensation in King type II curves treated with Cotrel-Dubousset instrumentation. Strict guidelines for selective thoracic fusion. Spine 1992;17:S274-81.

31. Hibbs RA. A report of fifty-nine cases of scoliosis treated by the fusion operation. J Bone Joint Surg 1924;6:3-37.

32. Ferguson AB. The study and treatment of scoliosis. Southern Med J 1930;23:116-20.

33. Butte FL. Scoliosis treated by the wedging jacket. Selection of the area to be fused. J Bone and Joint Surg 1938;20:1-22.

34. Risser JC. Scoliosis: past and present. J Bone Joint Surg Am 1964;46:167-99.

35. Harrington PR. Treatment of scoliosis. Correction and internal fixation by spine instrumentation. J Bone Joint Surg Am 1962;44-A:591-610.

36. Moe JH. Methods and technique of evaluating idiopathic scoliosis. In: The American Academy of Orthopaedic Surgeons: Symposiums on the spine. St. Louis: C.V. Mosby, 1969:196-240.

37. Moe JH. Methods of correction and surgical techniques in scoliosis. Orthop Clin North Am 1972;3:17-48.

38. Goldstein LA. The surgical management of scoliosis. Clin Orthop 1964;35:95-115.

39. Goldstein LA. Surgical management of scoliosis. J Bone and Joint Surg 1966;48-A:167-96.

40. Freeman BL. Scoliosis and kyphosis. In: Canale ST. editor. Campbell's operative orthopaedics. Ed. 10. Philadelphia: Mosby, 2003:1751-837.

41. Mielke CH, Lonstein JH, Denis F, et al. Surgical treatment of adolescent idiopathic scoliosis. A comparative analysis. J Bone Joint Surg Am 1989;71:1170-7.

42. Kalen V, Conklin M. The behavior of the unfused lumbar curve following selective thoracic fusion for idiopathic scoliosis. Spine 1990;15:271-4.

43. King HA. Analysis and treatment of Type II idiopathic scoliosis. Orthop Clin North Am 1994;25:225-37.

44. Winter RB, Lonstein JE, Denis F. How much correction is enough? Spine (Phila Pa 1976) 2007;32:2641-3.

45. Dubousset J, Graf H, Miladi L, et al. Spinal and thoracic derotation with CD instrumentation. Orthop Trans 1986;10:36.

46. McAllister JW, Bridwell KH, Pruitt DL, et al. Decompensation produced by Cotrel-Dubousset derotation maneuver for idiopathic right thoracic scoliosis. Orthop Trans 1988;12:719.

47. Richards BS, Birch JG, Herring JA, et al. Frontal plane and sagittal plane balance following CotrelDubousset instrumentation for idiopathic scoliosis. Spine 1989; 14:733-7.

48. Arlet V, Marchesi D, Papin P, et al. Decompensation following scoliosis surgery: treatment by decreasing the correction of the main thoracic curve or "letting the spine go". Eur Spine J 2000;9:156-60.

49. Lenke LG, Betz RR, Harms J, et al. Adolescent idiopathic scoliosis. A new classification to determine extent of spinal arthrodesis. J Bone Joint Surg 2001;83:1169-81.

50. McHenry HM. Human Evolution. In: Ruse M, Travis J. editors. Evolution: The First Four Billion Years. Cambridge: The Belknap Press of Harvard University Press, 2009:263.

51. Haviland WA, Walrath D, Prins HEL, et al. Evolution and Prehistory: The Human Challenge. 10th Ed. Belmont: Wadsworth Publishing, 2013:162.

52. Roussouly P, Pinheiro-Franco JL. Biomechanical analysis 
of the spino-pelvic organization and adaptation in pathology. Eur Spine J 2011;20:609-18.

53. Machida M, Murai I, Miyashita Y, et al. Pathogenesis of idiopathic scoliosis. Experimental study in rats. Spine 1999;24:1985-9.

54. Dickson RA. The aetiology of spinal deformities. Lancet 1988;1:1151-5.

55. Dalleau G, Damavandi M, Leroyer P, et al. Horizontal body and trunk center of mass offset and standing balance in scoliotic girls. Eur Spine J 2011;20:123-8.

56. Roussouly P, Labelle H, Rouissi J, et al. Pre- and postoperative sagittal balance in idiopathic scoliosis: a comparison over the ages of two cohorts of 132 adolescents and 52 adults. Eur Spine J 2013;22:S203-15.

57. Mac-Thiong JM, Roussouly P, Berthonnaud E, et al. Sagittal parameters of global spinal balance: normative values from a prospective cohort of seven hundred nine Caucasian asymptomatic adults. Spine 2010;35:E1193-8.

58. Mac-Thiong JM, Labelle H, Roussouly P. Pediatric sagittal alignment. Eur Spine J 2011;20:586-90.

59. Pasha S, Baldwin K. Are we simplifying balance in adolescent idiopathic scoliosis? Clin Biomech (Bristol, Avon) 2018;51:91-8.

60. Dickson RA, Lawton JO, Archer IA, et al. The pathogenesis of idiopathic scoliosis. Biplanar spinal asymmetry. J Bone Joint Surg Br 1984;66:8-15.

61. Deacon P, Flood BM, Dickson RA. Idiopathic scoliosis in three dimensions. A radiographic and morphometric analysis. J Bone Joint Surg Br 1984;66:509-12.

62. Deacon P, Berkin CR, Dickson RA. Combined idiopathic kyphosis and scoliosis. An analysis of the lateral spinal curvatures associated with Scheuermann's disease. J Bone Joint Surg Br 1985;67:189-92.

63. Somerville EW. Rotational lordosis: the development of the single curve. J Bone Joint Surg Br 1952;34-B:421-7.

64. Archer IA, Dickson RA. Stature and idiopathic scoliosis. A prospective study. J Bone Joint Surg Br 1985;67:185-8.

65. Mac-Thiong JM, Labelle H, Charlebois M, et al. Sagittal plane analysis of the spine and pelvis in adolescent idiopathic scoliosis according to the coronal curve type. Spine 2003;28:1404-9.

66. Upasani VV, Tis J, Bastrom T, et al. Analysis of sagittal alignment in thoracic and thoracolumbar curves in adolescent idiopathic scoliosis: how do these two curve types differ? Spine 2007;32:1355-9.

67. Schlösser TP, Shah SA, Reichard SJ, et al. Differences in early sagittal plane alignment between thoracic and lumbar adolescent idiopathic scoliosis. Spine J 2014;14:282-90.
68. Xiong B, Sevastik J, Hedlund R, et al. Sagittal configuration of the spine and growth of the posterior elements in early scoliosis. J Orthop Res 1994;12:113-8.

69. Hilibrand AS, Tannenbaum DA, Graziano GP, et al. The sagittal alignment of the cervical spine in adolescent idiopathic scoliosis. J Pediatr Orthop 1995;15:627-32.

70. Moe JH. A critical analysis of methods of fusion for scoliosis: an evaluation in two hundred and sixty-six patients. J Bone Joint Surg Am 1958;40-A:529-54.

71. Berthonnaud E, Dimnet J, Roussouly P, et al. Analysis of the sagittal balance of the spine and pelvis using shape and orientation parameters. J Spinal Disord Tech 2005;18:40-7.

72. Legaye J, Hecquet J, Marty C, et al. Sagittal equilibration of the spine: relationship between pelvis and sagittal spinal curves in the standing position. Rachis 1993;5:215-26.

73. Legaye J, Duval-Beaupère G, Hecquet J, et al. Pelvic incidence: a fundamental pelvic parameter for threedimensional regulation of spinal sagittal curves. Eur Spine J 1998;7:99-103.

74. Rajnics P, Templier A, Skalli W, et al. The association of sagittal spinal and pelvic parameters in asymptomatic persons and patients with isthmic spondylolisthesis. J Spinal Disord Tech 2002;15:24-30.

75. Hanson DS, Bridwell KH, Rhee JM, et al. Correlation of pelvic incidence with low- and high-grade isthmic spondylolisthesis. Spine 2002;27:2026-9.

76. Vedantam R, Lenke LG, Keeney JA, et al. Comparison of standing sagittal spinal alignment in asymptomatic adolescents and adults. Spine 1998;23:211-5.

77. Vaz G, Roussouly P, Berthonnaud E et al. Sagittal morphology and equilibrium of pelvis and spine. Eur Spine J 2002;11:80-7.

78. Mac-Thiong JM, Labelle H, Berthonnaud E, et al. Sagittal spinopelvic balance in normal children and adolescents. Eur Spine J 2007;16:227-34.

79. Mac-Thiong JM, Labelle H, Berthonnaud E, et al. Sagittal Alignment of the Spine and Pelvis during Growth. Spine 2004;29:1642-7.

80. Voutsinas SA, MacEwen GD. Sagittal profiles of the spine. Clin Orthop Relat Res 1986;210:235-42.

81. Poncet P, Dansereau J, Labelle H. Geometric torsion in idiopathic scoliosis: three-dimensional analysis and proposal for a new classification. Spine 2001;26:2235-43.

82. Duval-Beaupère G, Schimdt C, Cosson P. A barycentremetric study of the sagittal shape of spine and pelvis: the conditions required for an economic standing position. Ann Biomed Eng 1992;20:451-62. 
83. Vialle R, Levassor N, Rillardon L, et al. Radiographic analysis of the sagittal alignment and balance of the spine in asymptomatic subjects. J Bone Joint Surg Am 2005;87:260-7.

84. Marty C, Boisaubert B, Descamps H, et al. The sagittal anatomy of the sacrum among young adults, infants, and spondylolisthesis patients. Eur Spine J 2002;11:119-25.

85. Bernhardt M, Bridwell KH. Segmental analysis of the sagittal plane alignment of the normal thoracic and lumbar spines and thoracolumbar junction. Spine (Phila $\mathrm{Pa}$ 1976) 1989;14:717-21.

86. Stokes IA, Sangole AP, Aubin CE. Classification of scoliosis deformity three-dimensional spinal shape by cluster analysis. Spine 2009;34:584-90.

87. Sangole AP, Aubin CE, Labelle H, et al. Threedimensional classification of thoracic scoliosis curves. Spine 2009;34:91-9.

88. Illés T, Tunyogi-Csapó M, Somoskeöy S. Breakthrough

Cite this article as: Kubat O, Ovadia D. Frontal and sagittal imbalance in patients with adolescent idiopathic deformity. Ann Transl Med 2020;8(2):29. doi: 10.21037/atm.2019.10.49 in three-dimensional scoliosis diagnosis: significance of horizontal plane view and vertebra vectors. Eur Spine J 2011;20:135-43.

89. Thong W, Parent S, Wu J, et al. Three-dimensional morphology study of surgical adolescent idiopathic scoliosis patient from encoded geometric models. Eur Spine J 2016;25:3104-13.

90. Fitzgerald R, Upasani VV, Bastrom TP, et al. ThreeDimensional Radiographic Analysis of Two Distinct Lenke 1A Curve Patterns. Spine Deform 2019;7:66-70.

91. Newton PO, Osborn EJ, Bastrom TP, et al. The 3D Sagittal Profile of Thoracic Versus Lumbar Major Curves in Adolescent Idiopathic Scoliosis. Spine Deform 2019;7:60-5.

92. Spurway AJ, Hurry JK, Gauthier L, et al. Threedimensional True Spine Length: A Novel Technique for Assessing the Outcomes of Scoliosis Surgery. J Pediatr Orthop 2017;37:e631-7. 